\title{
Coil Occlusion of Basilar Bifurcation Aneurysms: The Shape of Things to Come
}

Can. J. Neurol. Sci. 1999; 26: 170-171

For the tens of thousands of unsuspecting human beings who suffer the sudden, frightening experience of cerebral aneurysm rupture each year, a remarkable evolution in treatment is occurring. The earliest efforts at direct treatment were in the 1930s, when surgeons desperate to prevent fatal re-bleeding began to deliberately expose aneurysms at craniotomy. They used muscle to buttress the exterior ${ }^{1}$ and later to pack the interior ${ }^{2}$ of aneurysms. Quickly there followed the development of the neck clipping techniques ${ }^{3}$ which by the 1950 s became, and remain to this day, the most effective and lasting form of cure.

Now an alternative technique is challenging the traditional methods. On the premise that electrical thrombosis subtended by wire might cure an aneurysm through its parent vessel, ${ }^{4}$ Italian neurosurgeon/neuroradiologist Guido Guglielmi and Canadian neuroradiologist Fernando Viñuela performed endovascular occlusion of a human cerebral aneurysm using electrically thrombotic coils in March $1990 . .^{5}$ Necessary to their approach was the ability to detach the coil from the pushing wire used to deposit it within the aneurysm. This was accomplished by electrolysis at a solder made to join the coil and the pushing wire. The presence of the solder meant that the coil could be retrieved from the aneurysm if its position was unsatisfactory. It was this feature of "retrievability", almost an afterthought in the original concept, which heralded a new era in the treatment of cerebral aneurysms.

The idea of percutaneous cerebral aneurysm occlusion has enticed physicians for over 25 years. It implies a lower risk to the patient by precluding both the surgical retraction on the brain and the mobilization of the aneurysm from its neighbouring vessels. In no other vascular territory could this be more advantageous than at the basilar artery bifurcation. These aneurysms lie in the interpeduncular cistern, a natural crevice of the midbrain near the geometric centre of the human head. Aneurysms here are surrounded by sub-millimeter vessels upon which depend the generators of human consciousness. Small wonder that these aneurysms have been among the most highly exposed to the Guglielmi detachable coil (GDC) treatment. ${ }^{6-10}$

In this issue of the Journal, Redekop and co-authors provide us with a careful review of their experience with the detachable coil treatment in 40 patients with basilar bifurcation aneurysms. ${ }^{11}$ At least two-thirds of their patients were treated because the risk of surgical clipping was felt to be higher than the risk of coil occlusion. With only 15 patients at their institution undergoing surgery for basilar bifurcation aneurysms during the same time period ( 5 of them after a failed attempt at coiling), the authors clearly prefer GDC occlusion as the initial approach for most such aneurysms.

Out of 40 aneurysms, coil treatment proved technically possible in 30 . Coil herniation through a wide aneurysm neck was the commonest impediment. The problem appeared worse in unruptured aneurysms.

Of the 30 successfully coiled, early angiographic occlusion rates were very good, with 86 per cent of aneurysms either completely occluded or showing only a small neck remnant. The sta- bility of a complete occlusion (obtained in 12 survivors) was confirmed at early follow-up angiography. At an average of one year after treatment, all remained completely occluded. Conversely, the instability of subtotal or partial occlusion in 13 survivors with mostly small neck remnants was found: almost 70 per cent looked worse at follow-up, one third of these serious enough to warrant further treatment either with more coils or surgery within one year.

Clinical effectiveness was established, with not a single rebleeding from any aneurysm completely or incompletely occluded. Complications included bleeding ( 3 cases) and thromboembolic stroke ( 3 cases) resulting in 1 death and 3 permanent deficits for a combined morbidity and mortality rate of 10 per cent.

The authors have shown that coil treatment is feasible, safe and effective in preventing further bleeding in the majority of patients with basilar bifurcation aneurysms. They have also shown that the ability to cure the aneurysm, as assessed by angiography, is only moderate; in about half of the aneurysms a complete occlusion was obtained.

These results are similar to those obtained in other studies, ${ }^{6-10}$ and in a recent systematic review of 1,383 patients extracted from 48 studies published between 1990 and $1997 .{ }^{12}$ Permanent complications in the review occurred in 4 per cent; 54 per cent of aneurysms were completely occluded.

The challenges for endovascular aneurysm treatment will continue to be on 2 major fronts: safety and effectiveness. With regard to the latter, refinements in technique are underway or anticipated. The rotational angiography employed by the authors, and the emerging role for on-line three-dimensional angiography, ${ }^{13}$ are expected to improve visualization of the aneurysm neck and increase the likelihood of complete angiographic occlusion. Methods to reduce or eliminate the problem of coil herniation in wide-necked aneurysms are beginning to show some promise. These include the inflation of a balloon at the aneurysm neck during coil deposition, ${ }^{14,15}$ the possible use of more than one catheter to deposit coils, ${ }^{16}$ and the placement of a stent to bridge the aneurysm orifice prior to coiling the aneurysm sac. ${ }^{17}$ Modified coils which spread laterally in a third dimension have recently come into clinical use. Novel approaches yet to be used in humans include the delivery of fibroblast grafts grown directly on the platinum coils, ${ }^{18}$ and the addition of a detachable bag into which coils may be placed and constrained. ${ }^{19}$

Safety is another issue. The most common problem is thromboembolic ischemia. ${ }^{20}$ Most often the events are transient or nondisabling. More aggressive use of heparin in patients with aneurysmal hemorrhage, and careful procedural monitoring of activated clotting times, have seemed to reduce the risk. Also, higher current levels during coil detachment have shortened the detachment time and probably reduced the amount of thrombus formation at the coil solder.

Stephen P. Lownie London, Ontario 


\section{REFERENCES}

1. Dott NM: Intracranial aneurysmal formations. Clin Neurosurg 1969; 16: $1-16$.

2. Drake CG: Earlier times in aneurysm surgery. Clin Neurosurg 1985; 32: $41-44$.

3. Dandy WE: Intracranial aneurysm of the internal carotid artery: cured by operation. Ann Surg 1938; 107: 654-657.

4. Guglielmi G, Viñuela F, Sepetka I, Macellari V: Electrothrombosis of saccular aneurysms via endovascular approach. Part I: Electrochemical basis, technique and experimental results. J Neurosurg 1991; 75: 1-7.

5. Guglielmi G, Viñuela F, Dion J, Duckwiler G: Electrothrombosis of saccular aneurysms via endovascular approach. Part 2: Preliminary clinical experience. J Neurosurg 1991; 75: 8-14.

6. Guglielmi G, Viñuela F, Duckwiler G, et al: Endovascular treatment of posterior circulation aneurysms by electrothrombosis using electrically detachable coils. J Neurosurg 1992; 77: 515-524.

7. McDougall CG, Halbach VV, Dowd CF, et al: Endovascular treatment of basilar tip aneurysms using electrolytically detachable coils. J Neurosurg 1996; 84: 393-399.

8. Raymond J, Roy D, Bojanowski M, Moumdjian R, L'Espérance G: Endovascular treatment of acutely ruptured and unruptured aneurysms of the basilar bifurcation. J Neurosurg 1997; 86: 211219.

9. Klein G, Szolar DH, Leber KA, Karaic R, Hausegger KA et al: Basilar tip aneurysm: endovascular treatment with Guglielmi detachable coils - midterm results. Radiology 1997; 205: 191196.

10. Bavinzski G, Killer M, Gruber A, et al: Treatment of basilar artery bifurcation aneurysms by using Guglielmi detachable coils: a 6year experience. J Neurosurg 1999; 90: 843-852.
11. Redekop G, Willinsky R, Montanera W, et al: Endovascular occlusion of basilar bifurcation aneurysms with electrolytically detachable coils: clinical considerations, outcome and angiographic results. Can J Neurol Sci 1999; 26: 172-181.

12. Brilstra EH, Rinkel GJE, van der Graaf Y, van Rooij WJJ, Algra A: Treatment of intracranial aneurysms by embolization with coils. A systematic review. Stroke 1999; 30: 470-476.

13. Fahrig R, Fox AJ, Lownie S, Holdsworth DW: Use of a C-arm system to generate true three-dimensional computed rotational angiograms: preliminary in vitro and in vivo results. AJNR Am J Neuroradiol 1997; 18: 1507-1514.

14. Moret J, Cognard C, Weill A, Castaings L, Rey A: The "remodelling technique" in the treatment of wide neck intracranial aneurysms. Intervent Neuroradiol 1997; 3: 21-35.

15. Levy DI, $\mathrm{Ku} \mathrm{A}$ : Balloon-assisted coil placement in wide-necked aneurysms. Technical note. J Neurosurg 1997; 86: 724-727.

16. Baxter BW, Rosso D, Lownie SP: Double microcatheter technique for detachable coil treatment of large, wide-necked intracranial aneurysms. AJNR Am J Neuroradiol 1998; 19: 1176-1178.

17. Higashida RT, Smith W, Gress D, et al: Intravascular stent and endovascular coil placement for a ruptured fusiform aneurysm of the basilar artery. Case report and review of the literature. J Neurosurg 1997; 87: 944-949.

18. Kallmes DF, Williams AD, Cloft $\mathrm{HJ}$ et al. Platinum coil-mediated implantation of growth factor-secreting endovascular tissue grafts: an in vivo study. Radiology 1998; 207: 519-523.

19. Jeffree MA, Bryne JV, Royston DD, Deasy NP, Morris JH: The porous, guidewire-directed, detachable aneurysm liner; a new concept $n$ the endovascular treatment of intracranial aneurysms. AJNR Am J Neuroradiol 1999; 20: 774-779.

20. Pelz DM, Lownie SP, Fox AJ: Thromboembolic events associated with the treatment of cerebral aneurysms with Guglielmi detachable coils. AJNR Am J Neuroradiol 1998; 19: 1541-1547. 